\title{
SWAT use of gridded observations for simulating runoff - a Vietnam river basin study
}

\author{
M. T. Vu, S. V. Raghavan, and S. Y. Liong \\ Tropical Marine Science Institute (TMSI), National University of Singapore, 18 Kent Ridge Road, Singapore 119227, \\ Singapore
}

Correspondence to: M. T. Vu (tue@nus.edu.sg)

Received: 14 October 2011 - Published in Hydrol. Earth Syst. Sci. Discuss.: 6 December 2011

Revised: 6 June 2012 - Accepted: 9 July 2012 - Published: 16 August 2012

\begin{abstract}
Many research studies that focus on basin hydrology have applied the SWAT model using station data to simulate runoff. But over regions lacking robust station data, there is a problem of applying the model to study the hydrological responses. For some countries and remote areas, the rainfall data availability might be a constraint due to many different reasons such as lacking of technology, war time and financial limitation that lead to difficulty in constructing the runoff data. To overcome such a limitation, this research study uses some of the available globally gridded high resolution precipitation datasets to simulate runoff. Five popular gridded observation precipitation datasets: (1) Asian Precipitation Highly Resolved Observational Data Integration Towards the Evaluation of Water Resources (APHRODITE), (2) Tropical Rainfall Measuring Mission (TRMM), (3) Precipitation Estimation from Remote Sensing Information using Artificial Neural Network (PERSIANN), (4) Global Precipitation Climatology Project (GPCP), (5) a modified version of Global Historical Climatology Network (GHCN2) and one reanalysis dataset, National Centers for Environment Prediction/National Center for Atmospheric Research (NCEP/NCAR) are used to simulate runoff over the Dak Bla river (a small tributary of the Mekong River) in Vietnam. Wherever possible, available station data are also used for comparison. Bilinear interpolation of these gridded datasets is used to input the precipitation data at the closest grid points to the station locations. Sensitivity Analysis and Autocalibration are performed for the SWAT model. The NashSutcliffe Efficiency (NSE) and Coefficient of Determination $\left(R^{2}\right)$ indices are used to benchmark the model performance. Results indicate that the APHRODITE dataset performed very well on a daily scale simulation of discharge having a
\end{abstract}

good NSE of 0.54 and $R^{2}$ of 0.55 , when compared to the discharge simulation using station data (0.68 and 0.71$)$. The GPCP proved to be the next best dataset that was applied to the runoff modelling, with NSE and $R^{2}$ of 0.46 and 0.51 , respectively. The PERSIANN and TRMM rainfall data driven runoff did not show good agreement compared to the station data as both the NSE and $R^{2}$ indices showed a low value of 0.3. GHCN2 and NCEP also did not show good correlations. The varied results by using these datasets indicate that although the gauge based and satellite-gauge merged products use some ground truth data, the different interpolation techniques and merging algorithms could also be a source of uncertainties. This entails a good understanding of the response of the hydrological model to different datasets and a quantification of the uncertainties in these datasets. Such a methodology is also useful for planning on Rainfall-runoff and even reservoir/river management both at rural and urban scales.

\section{Introduction}

Rainfall runoff model is a typical hydrological modelling tool that determines the runoff signal which leaves the watershed basin from the rainfall signal received by the basin. Therefore, precipitation is the most important parameter in hydrological modelling. Soil and Water Assessment Tool (SWAT) (Arnold et al., 1998), used for rainfall runoff modelling in this study, was developed to quantify the runoff and concentration load due to the distributed precipitation and other meteorological data based on watershed topography, soil and land use condition. A number of research studies 
that focus on basin hydrology have used the SWAT model to simulate runoff (Ashraf et al., 2011; Mengistu and Sorteberg, 2012; Raghavan et al., 2011; Simon and Inge, 2010; Easton et al., 2010; Pohlert et al., 2007; Cau and Paniconi, 2007).

Ashraf et al. (2011) used SWAT on the Mimbres river basin in southwestern New Mexico, USA with different spatially distributed rainfall data to simulate river discharge, however, these datasets did not provide good simulation results. Raghavan et al. (2011) used the SWAT model to assess the future (2071-2100) stream flow over Sesan catchment in Vietnam using the downscaled precipitation from Regional Climate Model (RCM) Weather Research Forecast (WRF) driven by the global climate model ECHAM5. Their findings proved that there is a marginal increase in stream flow in this region during flood season (June to October) during the end of the century. Easton et al. (2010) used SWAT to simulate runoff and erosion in the Blue Nile basin with source of runoff from Ethiopia. Simon and Inge (2010) also evaluated some remote-sensing based rainfall products using MIKE SHE hydrological model (developed by the Danish Hydrological Institute) for Senegal river basin in West Africa for daily time step between 2003-2005 and suggested that some of the datasets produced good NSE and $R^{2}$ indices. Pohlert et al. (2007) modified the SWAT model (SWAT-N) to predict discharge at mesoscale Dill catchment (Germany) for 5-yr period. Apart from the above research studies, the use of gridded observation data which include both station data, gridded rain gauge data and satellite based data to hydrological model SWAT have not been applied in many studies, especially in this study region over Vietnam. Hence, our research shows an approach of ensemble rainfall data source as an input to hydrological model to evaluate the application of these gridded data keeping in mind future policy implications in a changing climate and management of water resources in this region.

Many research institutes around the world have developed gridded observational precipitation data for global and regional domains under different temporal and spatial resolutions. Some of them such as the CRU (Climatic Research Unit, from the University of East Anglia, UK) and UDEL (University of Delaware precipitation dataset) are constructed based on the ground truth data for the world domain with a grid size of $0.5^{\circ}(\sim 50 \mathrm{~km})$ in monthly intervals. Some other datasets, mostly satellite based such as TRMM (Tropical Rainfall Measuring Mission), a joint endeavour between NASA (National Aeronautic and Space Administration) and JAXA (Japan Aerospace Exploration Agency), PERSIANN (Precipitation Estimation from Remotely Sensed Information using Artificial Neural Networks) from the Center for Hydrometeorology and Remote Sensing, University of California, Irvine, USA GPCP (Global Climatology Precipitation Product) from NASA, provide data in daily and subdaily scales at resolutions between $0.25^{\circ}$ to $1^{\circ}$ which are ideal for rainfall runoff modelling. Few datasets such as the APHRODITE (Asian Precipitation Highly Resolved Observational Data Integration Towards Evaluation of water resources), developed by Meterological Research Institute (MRI), Japan and GHCN2 (a modified version of the Global Historical Climatology Network) from University of Washington, USA, provide a daily time series of rainfall data from many ground truth data collected from different sources. The reanalysis data such as NCEP/NCAR (National Centers for Environmental Prediction/National Center for Atmospheric Research) and ECMWF (European Centre for Medium Range Weather Forecasting) European Reanalysis ERA40 provide data at daily and sub-daily scales, although at relatively coarser spatial resolutions of about $2.5^{\circ}$. Detailed descriptions of these above datasets are provided later in this paper. These differences in datasets indicate there are still huge uncertainties amongst available observational data and comprehensive datasets at high spatial and temporal resolution need to be developed for the use by the scientific community. This paper uses the daily rainfall products of the APHRODITE, TRMM, GPCP, PERSIANN, GHCN2 and the NCEP/NCAR reanalysis datasets for use in the SWAT model. The SWAT model usually takes as input, rainfall data time series from gauged stations. Hence, an interpolation method is required to compute the station data (at a particular grid point) from the gridded observation data. Linear interpolation is one of the simplest methods used for such purposes. The bilinear interpolation method is an extension of the linear interpolation for interpolating functions of two variables on a regular grid and, hence, we use the bilinear interpolation method to extract precipitation values for station data, at a grid point.

The aim of this paper is to test the suitability of the application of gridded observational precipitation datasets to generate runoff over the study region, especially when station data are not available. This has implications for climate change studies also when climate model inputs will be available for runoff modelling. In doing so, the climate model derived rainfall estimates need to be compared to station data, in whose absence, those results need to be compared against the globally available gridded data products. This will help in the application of gridded precipitation data in climate change studies where rainfall data obtained from regional climate modelling will be applied to quantify the change in future runoff under different climate change scenarios.

\section{Study region, model and data}

\subsection{Study catchment}

The Dak Bla river catchment lies in the central highland of Vietnam and the Dak Bla river is a small tributary of the Mekong river. There are 3 rainfall stations Kon Plong, Kon Tum and Dak Doa inside and outside of the catchment (Fig. 1). There is a gauging discharge station at Kon Tum 


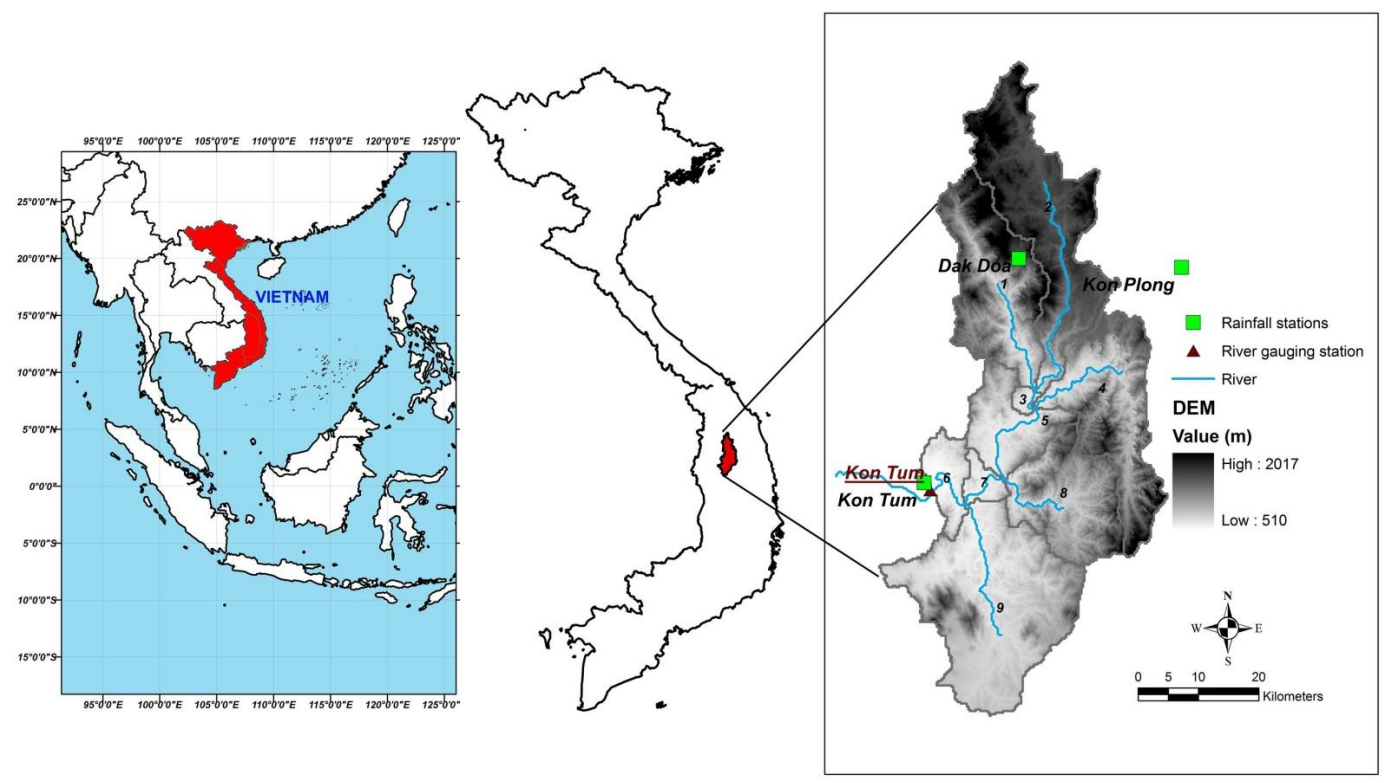

(a)

(b)

(c)

Fig. 1. Study region: (a) the country Vietnam is shown within the Southeast Asia region; (b) the location of the catchment in Vietnam; (c) the catchment area

that measures the runoff at the downstream end of the river. Its total area from upstream to Kon Tum station is $2560 \mathrm{~km}^{2}$ and the river length is about $80 \mathrm{~km}$. The watershed is covered mostly by tropical forests which are classified as: tropical evergreen forest, young forest, mixed forest, planned forest and shrub. The local economy is based heavily on rubber and coffee plantations on typical red basalt soil (Fig. 2) in which, by the end of 2010, coffee was accounted for $10 \%$ of Vietnam's annual export earnings (Ha and Shively, 2007). With the advantage of topography of this central highland region, there is a very high potential of constructing hydropower dams in this region and to store surface water for multipurpose needs: irrigation, electric generation and flood control. Upper Kon Tum hydropower with installed capacity of $210 \mathrm{MW}$ has been under construction since 2009 (to be completed in 2014) in the upstream region of Dak Bla river and at $110 \mathrm{~km}$ downstream, there is the Yaly hydropower plan (installed capacity 720 MW - second biggest hydropower project in Vietnam) which is in operation since 2001. Forecasting runoff flow from rainfall is therefore quite an important task in this region in order to operate the hydropower dam regulation as well as for irrigation purposes.

The climate of this region follows the pattern of central highland in Asia with an annual average temperature of about $20-25^{\circ} \mathrm{C}$ and total annual average rainfall of about 1500 $3000 \mathrm{~mm}$ with high evapotranspiration rate of about 1000 $1500 \mathrm{~mm}$ per annum. The southwest monsoon season (May to September) brings more rain to this region. Since the purpose of this study is to compare the use of different gridded rainfall products to regional stream flow, the model configu- ration has been simplified: the whole region is divided into 9 sub-basins by default threshold setup based on a Digital Elevation Model, DEM as seen in Fig. 1c, dominant landuse, soil, slope being applied in HRU definition and autocalibration method been applied using ParaSol (which will be described later in Sect. 3).

\subsection{SWAT model}

SWAT is a river basin scale model, developed by the United States Department of Agriculture (USDA) - Agriculture Research Service (ARS) in the early 1990s. It is designated to work for a large river basin over a long period of time. Its purpose is to quantify the impact of land management practices on water, sediment and agriculture chemical yields with varying soil, land use and management conditions. SWAT version 2005 with an ArcGIS user interface is used in this paper. There are two methods for estimating surface runoff in the SWAT model: Green \& Ampt infiltration method, which requires precipitation input in sub-daily scale (Green and Ampt, 1911) and the Soil Conservation Service (SCS) curve number procedure (USDA Soil Conservation Service, 1972) which uses daily precipitation, the latter, therefore, was selected for model simulations. Retention parameter is very important in SCS method and it is defined by Curve Number $(\mathrm{CN})$ which is a sensitive function of the soil's permeability, land use and antecedent soil water conditions. SWAT model offers three options for estimating potential evapotranspiration, PET: Hargreaves (Hargreaves et al., 1985), PriestleyTaylor (Priestley and Taylor, 1972) and Penman-Monteith 

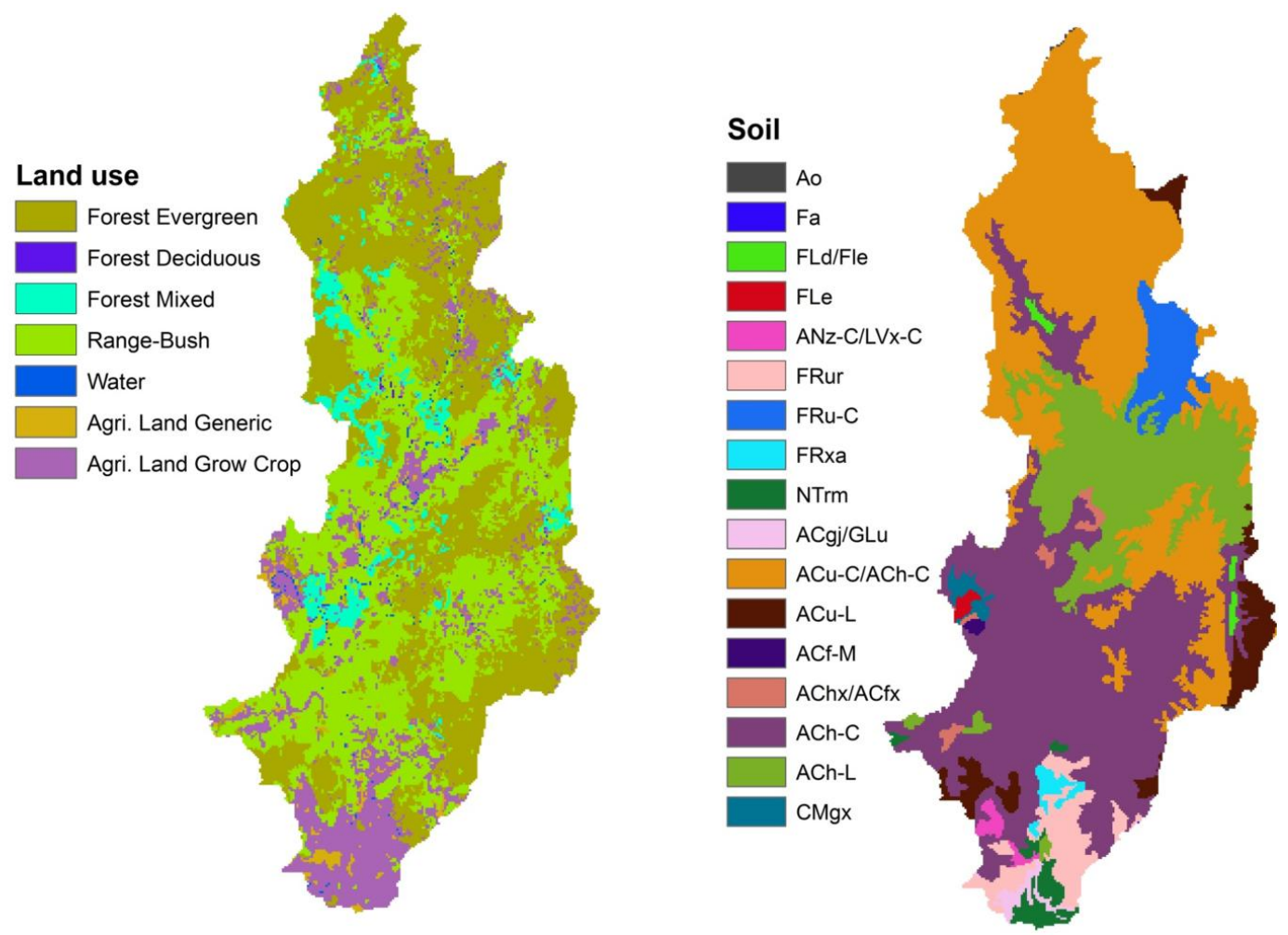

Fig. 2. Land use and soil map of Dak Bla river basin.

(Monteith, 1965). While Hargreaves method requires only maximum, minimum and average surface air temperature, the Priestley-Taylor method needs solar radiation, surface air temperature and relative humidity and the inputs for PenmanMonteith method are the same as Priestley-Taylor, in addition to requiring the wind speed. Due to limitations in the available meteorological data, the Hargreaves method is applied in this study. In the SWAT model, the land area in a sub-basin is divided into what are known as Hydrological Response Units (HRUs). In other words, a HRU is the smallest portion that combines different land use and soil type by overlaying their spatial map. All processes such as surface runoff, PET, lateral flow, percolation, and soil erosion are carried out for each HRU (Arnold and Fohrer, 2005).

In this study, SWAT input requires spatial data like DEM, land use and soil map. The DEM of $250 \mathrm{~m}$ was obtained from the Department of Survey and Mapping (DSM), Vietnam. Land use map, version 2005, was taken from the Forest Investigation and Planning Institute (FIPI) of Vietnam. Soil map was implemented by the Ministry of Agriculture and Rural Development (MARD) based on the FAO (Food and Agriculture Organization) category. Precipitation data in daily format was used from 1995-2005 from 3 stations mentioned earlier for both calibration and validation processes (Figs. 1 and 2). Daily maximum and minimum temperatures were obtained from the local authority from the Kon Tum meteorological station. The average daily temperature was calculated from the daily maximum and minimum temperatures.

\subsection{Gridded observation and reanalysis data}

The different observational data that were used in this study are described in this section. The interpolation method that was used to ascertain rainfall values closer to the chosen stations is also described.

\section{APHRODITE}

A daily gridded precipitation dataset for 1951-2007 was created by collecting rain gauge observation data across Asia through the activities of the Asian Precipitation Highly Resolved Observational Data Integration Towards the Evaluation of Water Resources project. However, it is important to notice that the gridded precipitation values from the APHRODITE project is available only for all land area covering Monsoon Asia, Middle East and Russia and not available for oceanic areas. Version V1003R1 with spatial resolution of $0.25^{\circ}$ for the Monsoon Asia region is used in this paper. More information can be found in Yatagai et al. (2009).

\section{TRMM}

The Tropical Rainfall Measuring Mission aims to monitor tropical and subtropical precipitation and to estimate its 
associated latent heating (GES DISC, 2010). The daily product TRMM 3B42 was used in this study. The purpose of the $3 \mathrm{~B} 42$ algorithm is to produce TRMM-adjusted mergedinfrared (IR) precipitation and root-mean-square (RMS) precipitation-error estimates. The version $3 \mathrm{~B} 42$ has a 3 hourly temporal resolution and a $0.25^{\circ}$ by $0.25^{\circ}$ spatial resolution. The spatial coverage extends from $50^{\circ} \mathrm{S}$ to $50^{\circ} \mathrm{N}$ and $0^{\circ}$ to $360^{\circ} \mathrm{E}$. The daily accumulated rainfall product was derived from this 3-hourly product.

\section{PERSIANN}

PERSIANN algorithm provides global precipitation estimation using combined geostationary and low orbital satellite imagery. Although other sources of precipitation observation, such as ground based radar and gauge observations, are potential sources for the adjustment of model parameters, they are not included in the current PERSIANN product generation. The evaluation of the PERSIANN product using gauge and radar measurements is ongoing to ensure the quality of generated rainfall data. PERSIANN generates near-global $\left(50^{\circ} \mathrm{S}-50^{\circ} \mathrm{N}\right)$ product at a $0.25^{\circ}$ spatial resolution having 3 hourly temporal resolutions (Wheater, 2007). The daily data used in this study is aggregated from this 3 hourly dataset.

\section{GPCP}

The GPCP version 1DD (Degree Daily) V1.1 is computed by the GPCP Global Merge Development Centre, at the NASA/GSFC (Goddard Space Flight Center) Laboratory for Atmospheres. It uses the best quasi-global observational estimators of underlying statistics to adjust quasi-global observational datasets that have desirable time/space coverage. Compared to its previous model, version $2.1\left(2.5^{\circ} \times 2.5^{\circ}\right)$, the 1DD V1.1 has undergone extensive development work which include diurnally varying calibrations, extension back in time, additional sensors, direct use of microwave estimates and refined combination approaches. The current dataset extends from October 1996 to present day with a grid size $1^{\circ} \times$ $1^{\circ}$ longitude-latitude. More information about this dataset can be found in Huffman et al. (2001).

\section{GHCN2}

This is the modified version of the Global Historical Climatology Network and has been documented in detail by Adam and Lettenmaier (2003). For simplicity, we call it GHCN2 in this paper. It includes precipitation, air temperature and wind speed data and was developed by the Department of Civil and Environmental Engineering, University of Washington. The precipitation dataset is based on gauge based measurement and is available on land only. Daily precipitation data from 1950 to 2008 with a spatial resolution of $0.5^{\circ} \times 0.5^{\circ}$ was used in this study.

\section{NCEP reanalysis}

The National Centers for Environmental Prediction (NCEP) and National Center for Atmospheric Research (NCAR) have developed a 40-yr record of global re-analyses (Kalnay et al., 1996) of atmospheric fields in support of the needs of the research and climate monitoring communities. The NCEP/NCAR re-analyses provide information at a horizontal resolution of T62 $(\sim 209 \mathrm{~km})$ with 28 vertical levels. This dataset has now been extended from 1948 onwards and is available until date. Most of the variables are available at a resolution of $2.5^{\circ} \times 3.75^{\circ}$ on a regular latitude and longitude grid. The Table 1 shows the different datasets used in this study.

\section{Sensitivity analysis, calibration and validation}

Sensitivity analysis is a method to analyse the sensitivity of model parameters to model output performance. In SWAT, there are 26 parameters sensitive to water flow, 6 parameters sensitive to sediment transport and other 9 parameters sensitive to water quality. The sensitivity analysis method coupled in SWAT model uses Latin Hypercube One-factorAt-a-Time method (LH-OAT). This method combines the robustness of the Latin Hypercube (McKay et al., 1979, 1988) sampling that ensures that the full range of all parameters has been sampled with the precision of an OAT design (Morris, 1991) assuring that the changes in the output in each model run can be unambiguously attributed to the parameter that was changed (Van Griensven et al., 2006). The first 2 columns of Table 2 show the order of the 11 parameters which are sensitive to model output. Auto-calibration using ParaSol is applied to those most sensitive parameters to find the appropriate range of parameters that yield the best result compared to observed discharge data at the gauging station. ParaSol is an optimisation and a statistical method for the assessment of parameter uncertainty and it can be classified as being global, efficient and being able to deal with multiple objectives (Van Griensven and Meixner, 2006). This optimisation method uses the Shuffled Complex Evolution method (SCE-UA) which is a global search algorithm for the minimisation of a single function for up to 16 parameters (Duan et al., 1992). It combines the direct search method of the simplex procedure with the concept of a controlled random search of Nelder and Mead (1965). The sum of the squares of the residuals (SSQ) is used as an objective function aiming at estimating the matching of a simulated series to a measured time series.

The SWAT model was run in a daily scale. The calibration period was done for the years 2000-2005 with the first year as the warm up period and the validation using 1995-2000 period. Model sensitivity analysis was applied for the runoff parameters and the Auto-calibration was done using the ParaSol method for 11 parameters that have the highest ranking 
Table 1. Gridded observations and Reanalysis datasets used in the study.

\begin{tabular}{lllll}
\hline DATASET & Period & Resolution $\left(^{\circ}\right)$ & Temporal Scale & Region \\
\hline APHRODITE & $1951-2007$ & 0.25 & daily & Monsoon Asia \\
TRMM & 1998-present & 0.25 & 3 hourly & Near Global \\
PERSIANN & 2000-present & 0.25 & 3 hourly & Near Global \\
GPCP & 1997-present & 1.00 & daily & Global \\
GHCN2 & $1950-2008$ & 0.5 & daily & Near Global \\
NCEP & $1957-2003$ & 2.50 & daily & Global \\
\hline
\end{tabular}

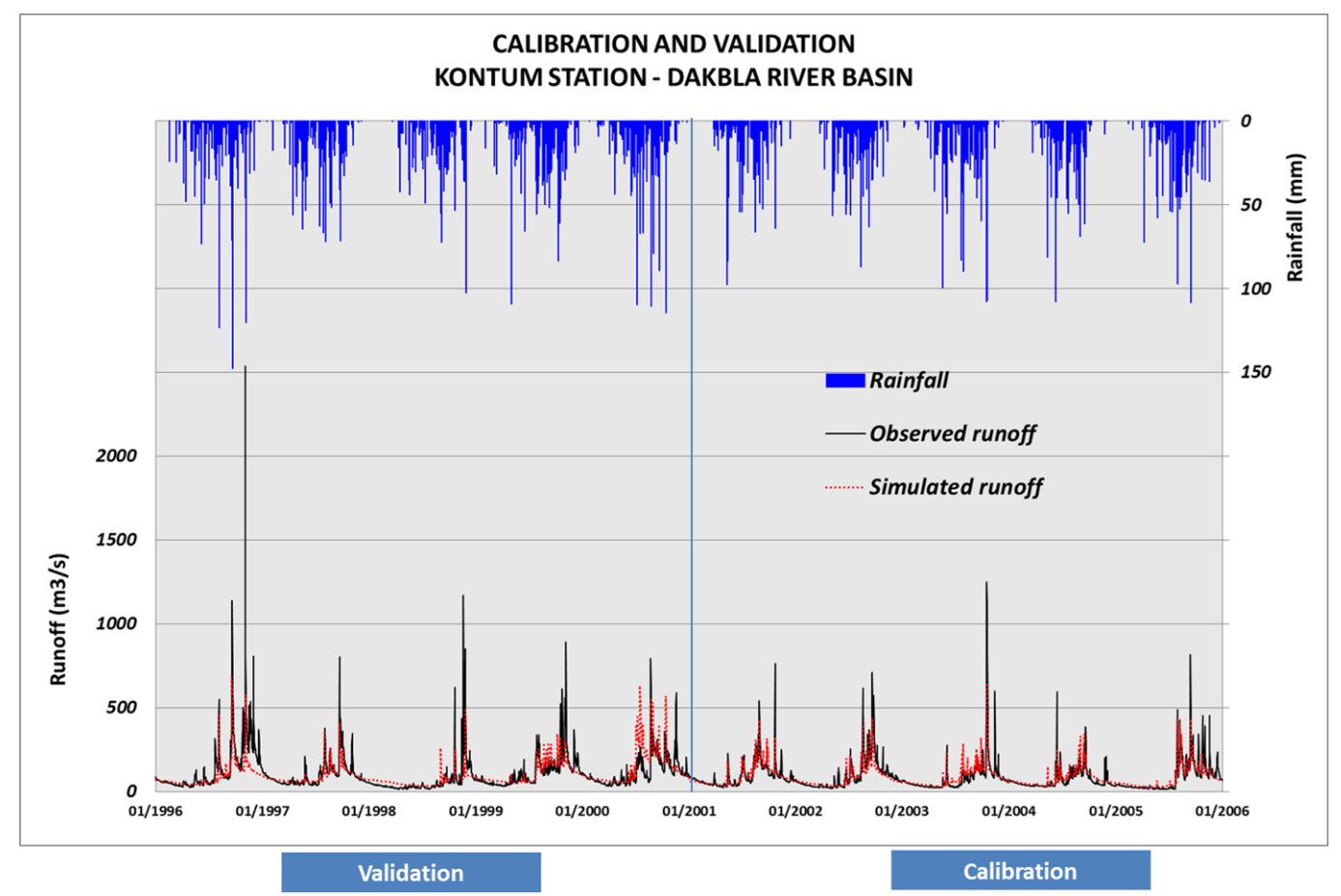

Fig. 3. Calibration and Validation using observed station rainfall for Dak Bla river basin at Kon Tum discharge gauging station.

in the sensitivity analysis part (Table 2). The Nash Sutcliffe Efficiency (NSE) (Nash and Sutcliffe, 1970) and coefficient of determination $\left(R^{2}\right)$ were used as comparing indices for the observed and simulated discharges from the SWAT model using different gridded precipitation. $R^{2}$ is the square of correlation coefficient (CC) and the NSE is calculated from Eq. (1) shown below. The NSE shows the skill of the estimates relative to a reference and it varies from negative infinity to 1 (perfect match). The NSE is considered to be the most appropriate relative error or goodness-of-fit measures available owing to its straightforward physical interpretation (Legates and McCabe, 1999).

$\mathrm{NSE}=1-\frac{\sum_{i=1}^{n}\left[\left(\mathrm{o}_{i}-\mathrm{s}_{i}\right)^{2}\right]}{\sum_{i=1}^{n}\left[\left(\mathrm{o}_{i}-\overline{\mathrm{o}}\right)^{2}\right]}$ where $\mathrm{o}_{i}$ and $\mathrm{s}_{i}$ are observed and simulated discharge dataset, respectively.

The NSE and $R^{2}$ for calibration and validation part are shown in Fig. 3. The indices, NSE and $R^{2}$, for the calibration phase were 0.68 and 0.71 , respectively, showing that the SWAT model was able to generate a reasonably good rainfall runoff process. The validation phase has lower values of indices compared to calibration with NSE and $R^{2}$ indices at 0.43 and 0.47 , respectively. This could be attributed to the errors in the precipitation data, either instrumental or recorded at these rainfall stations.

\section{Application to runoff over Dak Bla river basin using different gridded observation dataset}

The 6 different observed datasets were bi-linearly interpolated to the 3 rainfall stations for the study period of 
Table 2. Order of sensitive parameters and optimal value.

\begin{tabular}{|c|c|c|c|c|c|c|}
\hline $\begin{array}{l}\text { Sensitivity } \\
\text { Analysis } \\
\text { Order }\end{array}$ & Parameter & Description & Unit & $\begin{array}{l}\text { Parameter } \\
\text { range }\end{array}$ & $\begin{array}{l}\text { Initial } \\
\text { value }\end{array}$ & $\begin{array}{l}\text { Optima } \\
\text { value }\end{array}$ \\
\hline 1 & Alpha_Bf & Baseflow recession constant & days & $0-1$ & 0.048 & 0.02 \\
\hline 2 & $\mathrm{Cn} 2$ & Moisture condition II curve no & - & $35-98$ & 35 & 52.07 \\
\hline 3 & Ch_N2 & Manning $\mathrm{n}$ value for the main channel & - & $-0.01-0.3$ & 0.014 & 0.05 \\
\hline 4 & $\mathrm{Ch}_{-} \mathrm{K} 2$ & Effective hydraulic conductivity in main channel & $\mathrm{mm} \mathrm{hr}^{-1}$ & $-0.01-500$ & 0 & 76.74 \\
\hline 5 & Sol_K & Saturated hydraulic conductivity & $\mathrm{mm} \mathrm{hr}^{-1}$ & 0-2000 & 1.95 & 100.02 \\
\hline 6 & Sol_Awc & Available water capacity & $\mathrm{mm} \mathrm{mm}^{-1}$ & $0-1$ & 0.22 & 0.29 \\
\hline 7 & Surlag & Surface runoff lag coefficient & - & $1-24$ & 4 & 1.13 \\
\hline 8 & Esco & Soil evaporation compensation factor & - & $0-1$ & 0 & 1 \\
\hline 9 & Gwqmin & $\begin{array}{l}\text { Threshold water level in } \\
\text { shallow aquifer for base flow }\end{array}$ & $\mathrm{mm}$ & $0-5000$ & 0 & 0.12 \\
\hline 10 & Gw_Revap & Revap coefficient & - & $0.02-0.2$ & 0.02 & 0.2 \\
\hline 11 & Gw_Delay & Delay time for aquifer recharge & days & $0-500$ & 31 & 23.13 \\
\hline
\end{tabular}

2001-2005. Some analyses have been carried out to compare those observational gridded datasets against station data. Figure 4 displays the monthly average annual precipitation cycle and the statistical box plots for the 6 gridded observation datasets compared against observed station data. The annual cycle, as seen from the figure, is very useful to evaluate the seasons through the year. It is normally estimated from observational data or model output by taking the average of each month for a given number of years. This is a useful way of comparing the model and observations and is being used in many studies to compare data and trends (Peter et al., 2009). It is clearly seen from the pattern of precipitation annual cycle over these 3 rainfall stations that the observed data in black line shows that the Southwest monsoon season (from May to September) brings more rain to this region with a peak of rainfall in August. APHRODITE (blue) and PERSIANN (red) follow closely with observed pattern. GPCP (cyan) is slightly lagging in mimicking the peak of the rainfall. The TRMM (green) and GHCN2 (magenta) data are not as good when compared to the other 3 datasets. The NCEP/NCAR reanalysis data (yellow) performs poorly, probably due to its coarse spatial resolution. The box plot is an efficient statistical method for displaying a five-number data summary: median, upper quartile (75th percentile), lower quartile ( 25 th percentile), minimum and maximum value. The range of the middle two quartiles is called an inter-quartile range represented by a rectangle and if the median line in the box is not equidistant from the hinges then data is supposed to be skewed. The average monthly for 5yr period precipitation box plots over 3 rainfall stations for 6 datasets are plotted in Fig. 4. Looking at the inter-quartile range of the gridded datasets compared to the station data, the APHRODITE and GPCP have the same range at the 3 stations while PERSIANN, TRMM and GHCN2 are slightly narrower with NCEP having the lowest range amongst them all and these showcase the uncertainties among them.
Overall, the following statistics were applied to evaluate the gridded datasets with reference to the station data: linear correlation coefficient (CC), mean error (ME), mean absolute error (MAE) and bias as shown in their respective equations below:

$$
\begin{aligned}
\mathrm{CC} & =\frac{\sum_{i=1}^{n}\left[\left(x_{i}-\bar{x}\right)\left(y_{i}-\bar{y}\right)\right]}{\sqrt{\sum_{i=1}^{n}\left[\left(x_{i}-\bar{x}\right)^{2}\right] \sum_{i=1}^{n}\left[\left(y_{i}-\bar{y}\right)^{2}\right]}} \\
\mathrm{ME} & =\frac{1}{n} \sum_{i=1}^{n}\left(x_{i}-y_{i}\right) \\
\mathrm{MAE} & =\frac{1}{n} \sum_{i=1}^{n}\left|\left(x_{i}-y_{i}\right)\right| \\
\mathrm{Bias} & =\frac{\sum_{i=1}^{n} x_{i}}{\sum_{i=1}^{n} y_{i}}
\end{aligned}
$$

where $x$ and $y$ are gridded and local station dataset, respectively. The best value for $\mathrm{CC}$ and bias are 1 (unit-less), ME and MAE are $0(\mathrm{~mm})$, for precipitation. It has been suggested that MAE could be used instead of the Root-Mean-SquareError (RMSE) to avoid the effects of large outliers (Legates and McCabe, 1999). The comparison statistics for 3 rainfall stations on a daily scale over a 5-yr period 2001-2005 are shown in Table 3. In general, the CC of APHRODITE is the best for the 3 stations with a value above 0.65 followed by TRMM, GPCP and PERSIANN, in rank order. The GHCN2 and NCEP/NCAR data nearly have no correlation showing a zero value of CC. The bias for APHRODITE is very low (much closer to 1) for 3 stations while for GHCN2 is the highest one. The ME for GHCN2 seemed to be the lowest one at Dakdoa and Kon Tum stations which are inside the 
Table 3. Comparison statistics of gridded data with reference to local station for daily value over 5-yr period 2001-2005.

\begin{tabular}{lrrrrrr}
\hline Statistic & APHRODITE & TRMM & PERSIANN & GPCP & GHCN2 & NCEP \\
\hline \multicolumn{7}{c}{ Dakdoa } \\
\hline CC & 0.67 & 0.32 & 0.24 & 0.31 & 0.04 & -0.02 \\
ME & -0.22 & -0.99 & -0.61 & 0.18 & 0.09 & 0.30 \\
MAE & 3.96 & 5.63 & 6.29 & 6.19 & 7.67 & 8.25 \\
Bias & 0.96 & 0.41 & 0.32 & 0.29 & 0.18 & 0.23 \\
\hline \multicolumn{7}{c}{ Konplong } \\
\hline CC & 0.66 & 0.46 & 0.34 & 0.41 & 0.03 & -0.05 \\
ME & 0.33 & 0.27 & 0.29 & 1.16 & 0.75 & 0.57 \\
MAE & 3.87 & 5.20 & 5.73 & 6.00 & 7.39 & 7.67 \\
Bias & 1.08 & 0.51 & 0.34 & 0.30 & 0.18 & 0.21 \\
\hline \multicolumn{7}{c}{ Kon Tum } \\
\hline CC & 0.85 & 0.39 & 0.30 & 0.37 & 0.03 & -0.02 \\
ME & -0.13 & -0.86 & -0.86 & 0.11 & 0.08 & 0.36 \\
MAE & 2.64 & 5.46 & 5.86 & 5.89 & 7.83 & 8.38 \\
Bias & 0.97 & 0.42 & 0.30 & 0.28 & 0.18 & 0.23 \\
\hline
\end{tabular}

study catchment despite its very low $\mathrm{CC}$ and high bias. In contrast, the MAE of GHCN2 is the second highest after NCEP/NCAR (the coarse dataset). By observing the trends of 4 different statistics for 6 datasets, it is proposed that the role of $\mathrm{ME}$ in comparing those datasets is negligible whilst CC, MAE and bias show the same trend for these gridded data. Overall, this suggests that the APHRODITE dataset proves to be the best source of all gridded observations amongst all the ones considered in this study followed by TRMM, GPCP, PERSIANN, GHCN2 and NCEP, in that rank order.

The next step was to evaluate the performance of these different gridded products when applied to generate runoff for study region with the aforementioned calibrated parameters. These results are shown in daily and monthly scales from the daily simulations for a 5-yr period from 2001-2005. The NSE and $R^{2}$ indices for each dataset are displayed in Table 4 . These results also show that the APHRODITE dataset performs very well on the daily scale simulation of discharge when it has the closest NSE (0.54) and $R^{2}(0.55)$ indices when compared to the discharge simulation using station data ( 0.68 and 0.71 ). The GPCP proved to be the next best dataset that was applied to the runoff modelling, with NSE and $R^{2}$ of 0.46 and 0.51 , respectively. The PERSIANN and TRMM rainfall data driven runoff do not show good agreement compared to the station data as both the NSE and $R^{2}$ indices show a low value of 0.3 . GHCN2 and NCEP do not show good correlations.

On a monthly scale (Fig. 5), the GPCP (cyan) shows a very good match against the station data. Its NSE and $R^{2}$ value are about 0.8. The APHRODITE (blue) dataset shows good result with NSE and $R^{2}$ above 0.70 . The PERSIANN (red) dataset also shows reasonable agreement whilst the TRMM (green) data, despite its high temporal and spatial resolution, does not show a good match. The errors in satellite measurements could possibly be a factor that skews the benchmarking indices, but more work is needed to determine as to why the TRMM dataset fares less well than the others. The NCEP/NCAR reanalysis (yellow) does not show a good agreement even at capturing the stream flow patter, probably due its coarse resolution. The GHCN2 (magenta) performs better compared to the NCEP/NCAR dataset, but lags by two months for the peak discharge. The varied results by using these datasets indicate that although the gauge based and satellite-gauge merged products use some ground truth data, the different interpolation techniques and merging algorithms could also be a source of uncertainties.

These results indicate that although some uncertainties exist amongst these several datasets, the application of these gridded data prove useful for hydrological studies in the absence of station data and have implications for future studies to assess hydrological responses. The SWAT model also proves to be a good tool in such a modelling approach.

\section{Conclusions}

The SWAT model was applied for a catchment in central highland of Vietnam. The first part of the paper focused on the sensitivity analysis and auto calibration which were conducted for a 5-yr period from 2001-2005. The benchmarking indices prove that SWAT is a good and reliable hydrological model to simulate the rainfall runoff process for this catchment and that the gridded observational datasets can be a good substitute for station data over regions where robust observed data are not available. 


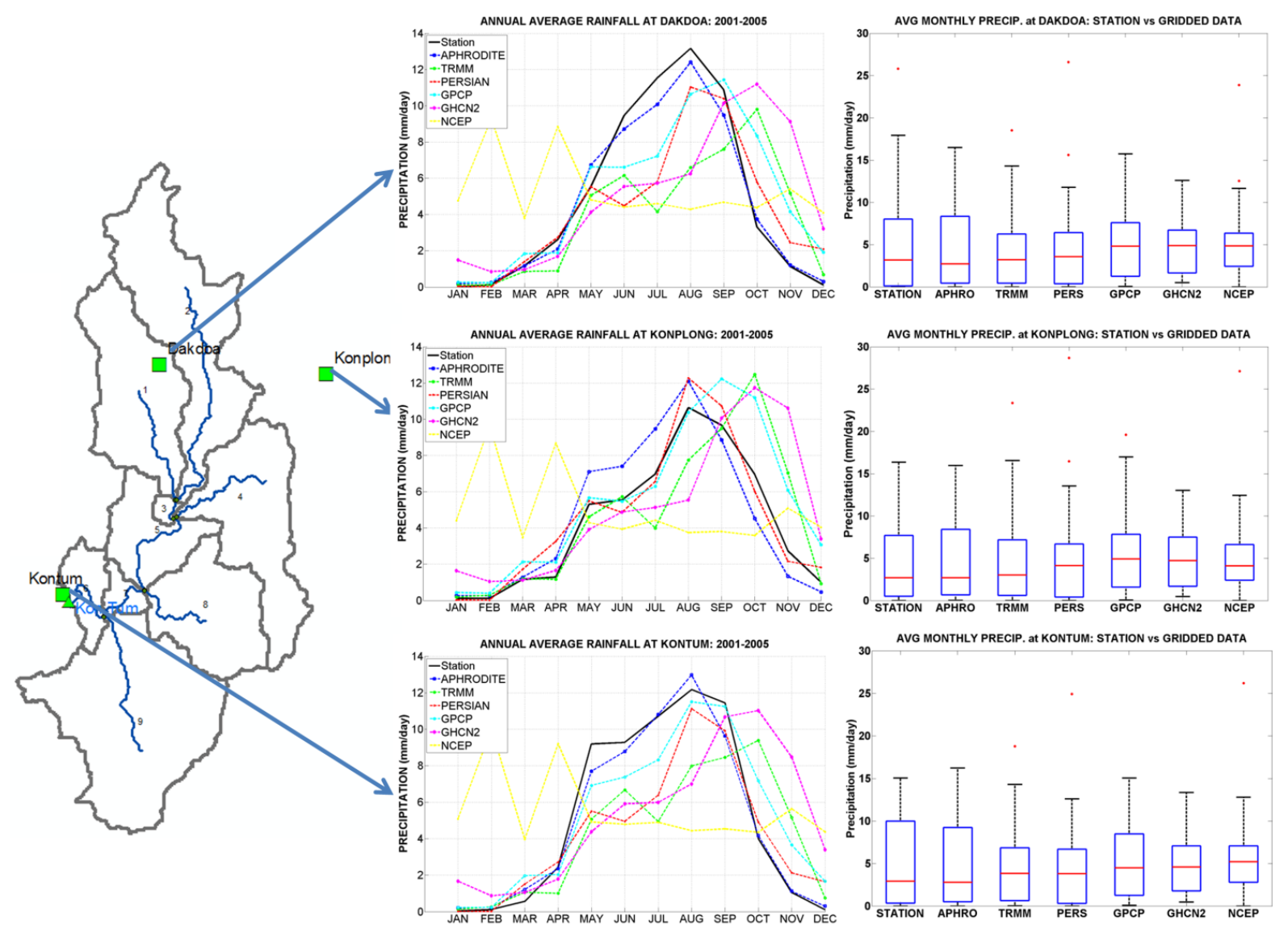

Fig. 4. Annual cycle and box plots for observed station and gridded observation precipitation at three rainfall stations in study region, daily data from 2001-2005.

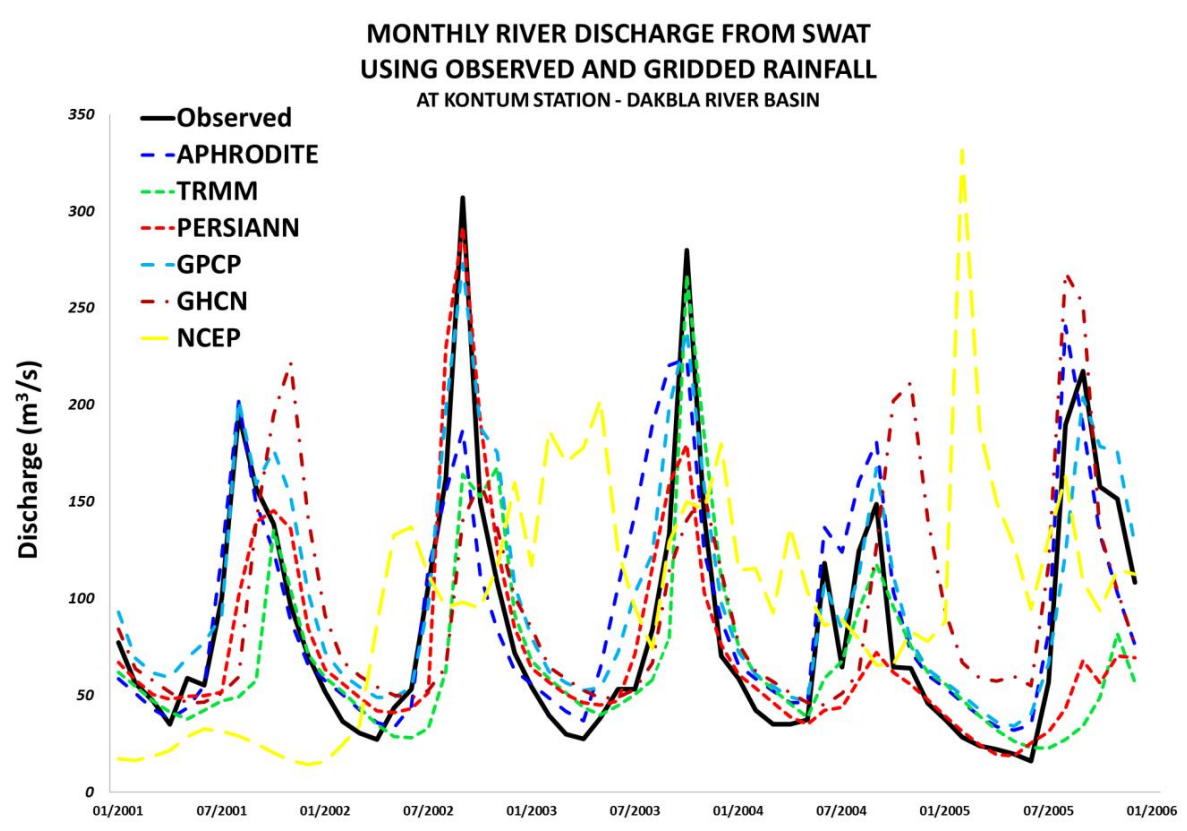

Fig. 5. Application of station, gridded observations and Reanalysis data to stream flow discharge over Dak Bla river, monthly aggregated from daily data. 
Table 4. NSE and $R^{2}$ indices for gridded observation and Reanalysis data applied to runoff over Dak Bla river.

\begin{tabular}{lcccc}
\hline Data & \multicolumn{2}{c}{ Daily } & \multicolumn{2}{c}{ Monthly } \\
\hline & NSE & $R^{2}$ & NSE & $R^{2}$ \\
\hline Station & 0.68 & 0.71 & 0.86 & 0.88 \\
APHRODITE & 0.54 & 0.55 & 0.70 & 0.72 \\
TRMM & 0.28 & 0.32 & 0.27 & 0.36 \\
PERSIANN & 0.30 & 0.34 & 0.50 & 0.54 \\
GPCP & 0.46 & 0.51 & 0.80 & 0.88 \\
GHCN2 & -0.06 & 0.13 & 0.15 & 0.28 \\
NCEP & -0.78 & 0.01 & -1.13 & 0.01 \\
\hline
\end{tabular}

A quantification of the application of different gridded observation and reanalysis datasets was also done. Amongst the 6 different datasets used in this study, the APHRODITE data shows its best match to station data in daily scale and the satellite based GPCP 1DD data, despite its relatively coarser resolution proves that it is a very good precipitation dataset under a monthly scale. The uncertainties that exist in the different observational datasets are being highlighted from this study. Although the temporal and spatial resolution may be higher, the different sources of errors in these datasets need further investigation and much more work is needed to that end. Nevertheless, the usefulness and suitability of applying these gridded products has been highlighted and it is promising that in areas where there is a paucity of station observations, these gridded products can be used well for applications for rainfall runoff modelling. Further work is likely to use regional climate model outputs under a changing climate to study rainfall runoff with these gridded observations serving as the benchmark to quantify climate model simulated rainfall.

Edited by: A. Shamseldin

\section{References}

Adam, J. C. and Lettenmaier, D. P.: Adjustment of global gridded precipitation for systematic bias, J. Geophys. Res., 108, 1-14, 2003.

Arnold, J. G. and Fohrer, N.: SWAT2000: current capabilities and research opportunities in applied watershed modelling, Hydrol. Process., 19, 563-572, doi:10.1002/hyp.5611, 2005.

Arnold, J. G., Srinivasan, R., Muttiah, R. S., and Williams, J. R.: Large area hydrologic modelling and assessment, part I: Model development, J. Am. Wat. Res., 34, 73-89, 1998.

Ashraf, E.-S., Max, B., Manoj, S., Steve, G., and Alexander, F.: Alternative climate data sources for distributed hydrological modelling on a daily time step, Hydrol. Process., 25, 1542-1557, 2011.

Cau, P. and Paniconi, C.: Assessment of alternative land management practices using hydrological simulation and a decision support tool: Arborea agricultural region, Sardinia, Hydrol. Earth Syst. Sci., 11, 1811-1823, doi:10.5194/hess-11-18112007, 2007.
Duan, Q., Sorooshian, S., and Gupta, V.: Effective and efficient global optimisation for conceptual rainfall-runoff models, Water Resour. Res., 28, 1015-1031, 1992.

Easton, Z. M., Fuka, D. R., White, E. D., Collick, A. S., Biruk Ashagre, B., McCartney, M., Awulachew, S. B., Ahmed, A. A., and Steenhuis, T. S.: A multi basin SWAT model analysis of runoff and sedimentation in the Blue Nile, Ethiopia, Hydrol. Earth Syst. Sci., 14, 1827-1841, doi:10.5194/hess-14-1827-2010, 2010.

GES DISC (Goddard Earth Sciences - Data and Information Services Centre), available at: http://disc.gsfc.nasa.gov/ precipitation/trmm_intro.shtml, last access May 18, 2010.

Green, W. H. and Ampt, G. A.: Studies on soil physics, J. Agr. Sci., 4, 11-24, 1911.

Ha, D. T. and Shively, G.: Coffee Boom, Coffee Bust and Smallholder Response in Vietnam's Central Highlands, Rev. Dev. Econ., 2007.

Hargreaves, G. L., Hargreaves, G. H., and Riley, J. P.: Agriculture benefits for Senegal River basin, J. Irrig. Drain E.-Asce., 111, 113-124, 1985.

Huffman, G. J., Adler, R. F., Morrissey, M., Bolvin, D. T., Curtis, S., Joyce, R., McGavock, B., and Susskind, J.: Global Precipitation at One-Degree Daily Resolution from Multi-Satellite Observations, J. Hydrometeorol., 2, 36-50, 2001.

Kalnay, E., Kanamitsu, M., Kistler, R., Collins, W., Deaven, D., Gandin, L., Iredell, M., Saha, S., White, G., Woollen, J., Zhu, Y., Leetmaa, A., and Reynolds, R.: The NCEP/NCAR 40-Year Reanalysis Project, B. Am. Meteorol. Soc., 77, 437-471, 1996.

Legates, D. R. and McCabe, G. J.: Evaluating the use of "goodnessof-fit" measures in hydrologic and hydroclimatic model validation, Water Resour. Res., 35, 233-241, 1999.

McKay, M. D.: Sensitivity and Uncertainty Analysis Using a Statistical Sample of Input Values, in: Uncertainty Analysis, edited by: Ronen, Y., CRC Press, Boca Raton, Florida, 145-186, 1988.

McKay, M. D., Beckman, R. J., and Conover, W. J.: A comparison of three methods for selecting values of input variables in the analysis of output from a computer code, Technometrics, 21, 239-245, 1979.

Mengistu, D. T. and Sorteberg, A.: Sensitivity of SWAT simulated streamflow to climatic changes within the Eastern Nile River basin, Hydrol. Earth Syst. Sci., 16, 391-407, doi:10.5194/hess16-391-2012, 2012.

Monteith, J. L.: Evaporation and the environment. Symposia of the society for Experiemental Biology, Cambridge Univ. Press, London, UK, 205-234, 1965.

Morris, M. D.: Factorial sampling plans for preliminary computation experiements, Technometrics, 33, 161-174, 1991.

Nash, J. E. and Sutcliffe, J. V.: River flow forecasting through conceptual models, Part 1 - A discussion of principles, J. Hydrol., 10, 282-290, 1970.

Nelder, J. A. and Mead, R.: A simplex method for function minimization, Comput. J., 7, 308-313, 1965.

Peter, C., Chin, H.-N. S., Bader, D. C., and Bala, G.: Evaluation of a WRF dynamical downscaling simulation over California, Climatic Change, 95, 499-521, doi:10.1007/s10584-009-95835, 2009.

Pohlert, T., Breuer, L., Huisman, J. A., and Frede, H.-G.: Assessing the model performance of an integrated hydrological and biogeochemical model for discharge and nitrate load predictions, Hydrol. Earth Syst. Sci., 11, 997-1011, doi:10.5194/hess-11-997- 
2007, 2007.

Priestley, C. H. B and Taylor, R. J.: On the assessment of surface heat flux and evaporation using large scale parameters, Mon. Weather Rev., 100, 81-92, 1972.

Raghavan, V. S., Vu, M. T., and Liong, S. Y.: Assessment of future stream flow over the Sesan catchment of the Lower Mekong Basin in Vietnam, Hydrol. Process., doi:10.1002/hyp.8452, 2011.

Simon, S. and Inge, S.: Evaluation of remote-sensing-based rainfall products through predictive capability in hydrological runoff modelling, Hydrol. Process., 24, 879-891, 2010.

USDA Soil Conservation Service: SCS National Engineering Handbook, Section 4: Hydrology, Washington DC, 1972.
Van Griensven, A. and Meixner, T.: Methods to quantify and identify the sources of uncertainty for river basin water quality models, Water Sci. Technol., 53, 51-59, 2006.

Van Griensven, A., Meixner, T., Grunwald, S., Bishop, T., and Srinivasan, R.: A global sensitivity analysis method for the parameters of multi-variable catchment model, J. Hydrol., 324, 10-23, 2006.

Wheater, H., Sorooshian, S., and Sharma, K. D.: Hydrological Modelling in Arid and Semi-Arid Areas, International Hydrology Series, Cambridge University Press, p. 21, 2007.

Yatagai, A., Arakawa, O., Kamiguchi, K., Kawamoto, H., Nodzu, M. I., and Hamada, A.: A 44-year daily gridded precipitation dataset for Asia based on a dense network of rain gauges, SOLA, 5, 137-140, 2009. 